\title{
Heat transfer evaluation of industrial pneumatic cylinders
}

\author{
J F Carneiro ${ }^{1,2 *}$ and F Gomes de Almeida ${ }^{1,2}$ \\ ${ }^{1}$ Departamento de Engenharia Mecânica, Universidade do Porto, Portugal \\ ${ }^{2}$ Instituto de Engenharia Mecânica, IDMEC, Pólo, Portugal
}

The manuscript was received on 27 July 2005 and was accepted after revision for publication on 4 July 2006.

DOI: 10.1243/09596518JSCE188

\begin{abstract}
Automatic positioning devices are used worldwide in tasks such as handling or assembly, making them key components of modern manufacturing systems. Pneumatic solutions are usually less expensive than their electrical counterparts, are more reliable, and require less maintenance. However, the complex non-linear nature and high model order of pneumatic systems lead to a very difficult control task.

These problems make model order reductions and simplifications a common practice in servopneumatics. The heat transfer between air inside the cylinder and its environment is usually neglected or only indirectly accounted for, since it varies with the pressure, temperature, and speed of the actuator, which makes its experimental assessment difficult. In this work a simple and yet accurate procedure is presented on the basis of a thermal time constant, enabling its evaluation. The procedure is validated by simulation studies, and furthermore the heat conductance of three industrial actuators is experimentally determined.
\end{abstract}

Keywords: pneumatic actuators, heat transfer, systems modelling

\section{INTRODUCTION}

Pneumatic systems are widely used in industry owing to their high power-weight ratio, low maintenance, and low acquisition cost. However, they are mostly used on bang-bang applications since their motion control is difficult owing to air compressibility and high frictional forces. Therefore, pneumatic solutions do not compete with their electrical counterparts when average positioning accuracy, trajectory following, or different payloads during motion are required.

To overcome these problems, the last decade has witnessed the growing interest of researchers in this field. There are two main tasks to solve when dealing with pneumatic servosystems: modelling of the system and synthesis of a suitable control law. The main research focus in the field of servopneumatics has been the control task. Very different control laws can be found in the literature; to mention

* Corresponding author: DEMEGI, Faculdade de Engenharia da Universidade do Porto, Rua Dr. Roberto Frias, Porto 4200-465, Portugal.email: jpbrfc@fe.up.pt just a few, see references [1] and [2] for sliding-mode controllers, reference [3] for state feedback controllers, reference [4] for Lyapunov-based approaches, and reference [5] for neural network approaches. Another interesting subject in this field is the pulse width modulation approach which enables less expensive on-off valves to be used [6, 7].

The modelling task encompasses several items, namely the servovalve, the mechanical components of the actuator, and the thermodynamic laws inside its chambers. Classical literature on pneumatic servovalve and friction modelling can be found in references [8] and [9] respectively, and a more recent approach to the complete servosystem model can be found in reference [10].

In what concerns thermodynamic laws, theoretical results lead to a model in which the heat transfer coefficient between the cylinder walls and air inside it explicitly appears. Since the heat transfer coefficient is difficult to determine $[\mathbf{1 1}]$ and it is known to vary with the pressure, temperature, and speed of the actuator [12], the most typical procedure to handle this situation is to consider a polytropic process that allows the tuning of the polytropic 
index ranging from 1 (isothermal process) to 1.4 (adiabatic reversible process). Burrows [13] used a reversible adiabatic approach, Zalmanzon [14], Outbib and Richard [4], and Ning and Bone [3] an isothermal method, and Andersen [15] and Chitty and Lambert [16] a polytropic process.

In this paper an approach to evaluate the heat transfer coefficient between air inside the cylinder chamber and its environment is proposed on the basis of a simple experimental procedure allowing the assessment of thermal conductance. This methodology has been used in hydraulic accumulators $[\mathbf{1 7}, \mathbf{1 8}]$ and oleopneumatic suspensions [19] but, as far as the present authors' knowledge goes, its use in pneumatic cylinders has not yet been reported. It is used in this paper to determine experimentally the heat transfer coefficients of three different commercial pneumatic actuators.

This paper is organized as follows. Section 2 presents a short derivation of the thermodynamic model of a servopneumatic chamber. Section 3 presents the methodology used to determine an approximate heat transfer coefficient and the results obtained for three industrial pneumatic cylinders. Finally, section 4 will draw the main conclusions.

\section{THERMODYNAMIC MODEL OF A PNEUMATIC CHAMBER}

Consider the schematic figure of a pneumatic cylinder chamber shown in Fig. 1.

Assuming that air is a perfect gas, that the pressures and temperatures are homogeneous inside the chamber, and that kinetic and gravitational energy of the fluid, viscous work, and cylinder mass flow leakages are negligible, the Reynolds transport theorem [20] applied to mass and energy in a fixed

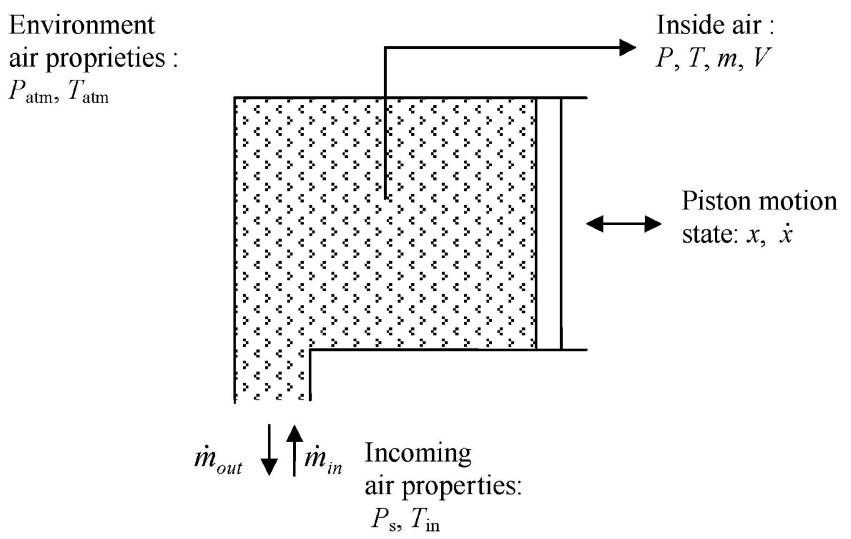

Fig. 1 Schematic diagram of the pneumatic cylinder chamber control volume with one-dimensional inlets and outlets results in

$$
\begin{aligned}
\frac{\mathrm{d} P}{\mathrm{~d} t}= & -\gamma \frac{P}{V} \frac{\mathrm{d} V}{\mathrm{~d} t}+\gamma \frac{R}{V} \dot{m}_{\mathrm{in}} T_{\mathrm{in}}-\gamma \frac{R}{V} \dot{m}_{\text {out }} T+\frac{\gamma-1}{V} \dot{Q} \\
\frac{\mathrm{d} T}{\mathrm{~d} t}= & \frac{T}{V} \frac{\mathrm{d} V}{\mathrm{~d} t}(1-\gamma)-\dot{m}_{\text {out }} \frac{R T^{2}}{V P}(\gamma-1) \\
& +\dot{m}_{\mathrm{in}} \frac{R T}{V P}\left(\gamma T_{\mathrm{in}}-T\right)+\frac{(\gamma-1) T}{P V} \dot{Q}
\end{aligned}
$$

Neglecting radiation heat transfer, the heat transfer $\dot{Q}$ between the air inside the cylinder and its interior walls can be expressed as [21]

$$
\dot{Q}=\lambda A_{q}(x)\left(T_{\mathrm{w}}-T\right)
$$

where $\lambda$ is the heat transfer coefficient between air and cylinder walls, $A_{q}(x)$ is the area of the heatexchanging surface between air and cylinder walls, and $T_{\mathrm{w}}$ is the temperature of that surface. This temperature is considered to be equal to the ambient temperature $\left(T_{\mathrm{w}}=T_{\mathrm{amb}}\right)$ for two reasons. First, the heat conductivity of air is much lower than the heat conductivity of common materials used in industrial cylinder walls. This means that the cylinder's internal wall temperature is essentially equal to its average temperature. Second, the thermal capacitance of the cylinder walls is very large when compared with the thermal capacitance of the contained air and therefore the average temperature of the walls is essentially equal to ambient temperature. Note that more complex models than this are available in the literature, namely models accounting for non-uniformity of air temperature inside the cylinder, leading to a dependence of heat transfer with the time derivative of temperature; see reference [22] for a recent study on the subject. However, these approaches are essentially used when modelling high-speed reciprocating machines with high compression ratios. The level of detail given by the model in equations (1), (2), and (3) is widely accepted in the servopneumatic literature and will therefore be considered as the thermodynamic model in subsequent work.

It is known that the heat transfer coefficient varies with the pressure, temperature, and speed of the piston [12]. The only study known by the present authors that experimentally estimates the heat transfer coefficient $\lambda$ in pneumatic actuators is that reported by Det [12]. In that work, Det stated that a constant heat transfer coefficient did not provide good agreement with experimental results for different charging-discharging processes. Therefore, the Eichelberg [23] model was simplified by 
neglecting heat transfer coefficient changes with the piston velocity and only accounting for the pressure and temperature dependence according to

$$
\lambda(P, T)=\lambda_{\mathrm{av}}\left(\frac{P T}{P_{\mathrm{av}} T_{\mathrm{av}}}\right)^{1 / 2}
$$

In this equation, $\lambda_{\mathrm{av}}=\lambda\left(P_{\mathrm{av}}, T_{\mathrm{av}}\right)$ is the heat transfer coefficient determined at the average values of pressure $P_{\mathrm{av}}$ and temperature $T_{\mathrm{av}}$. Det stated that $\lambda_{\mathrm{av}}=100 \mathrm{WK}^{-1} \mathrm{~m}^{-2}\left(T_{\mathrm{av}}=300 \mathrm{~K}\right.$ and $\left.P_{\mathrm{av}}=1.65 \mathrm{bar}\right)$ was the coefficient that best fitted the experimental air pressure evolution when a WABCO-CNOMO $\left(\phi=160 \mathrm{~mm}, \phi_{\mathrm{h}}=40 \mathrm{~mm}\right.$, and $\left.\mathrm{l}=150 \mathrm{~mm}\right)$ cylinder with a blocked rod was charged up to a pressure of $2.3 \times 10^{5} \mathrm{~Pa}$.

Considering now that the average pressure and temperature at normal (equilibrium) working conditions are defined as $P_{0}$ and $T_{0}$, the heat transfer coefficient can be determined from

$$
\lambda(P, T)=\lambda_{0}\left(\frac{P T}{P_{0} T_{0}}\right)^{1 / 2}
$$

where $\lambda_{0}=\lambda\left(P_{0}, T_{0}\right)$ is the heat transfer coefficient at $P_{0}$ and $T_{0}$. Substituting equation (5) in equations (3), (1), and (2) gives the differential equations ruling temperature and pressure evolution inside the chamber at normal working conditions as

$$
\begin{aligned}
\frac{\mathrm{d} P}{\mathrm{~d} t}= & -\gamma \frac{P}{V} \frac{\mathrm{d} V}{\mathrm{~d} t}+\gamma \frac{R}{V} \dot{m}_{\mathrm{in}} T_{\mathrm{in}}-\gamma \frac{R}{V} \dot{m}_{\text {out }} T \\
& +\frac{\gamma-1}{V} \lambda_{0}\left(\frac{P T}{P_{0} T_{0}}\right)^{1 / 2} A_{q}(x)\left(T_{\mathrm{amb}}-T\right) \\
\frac{\mathrm{d} T}{\mathrm{~d} t}= & \frac{T}{V} \frac{\mathrm{d} V}{\mathrm{~d} t}(1-\gamma)-\dot{m}_{\text {out }} \frac{R T^{2}}{V P}(\gamma-1) \\
& +\dot{m}_{\mathrm{in}} \frac{R T}{V P}\left(\gamma T_{\mathrm{in}}-T\right) \\
& +\frac{(\gamma-1) T}{P V} \lambda_{0}\left(\frac{P T}{P_{0} T_{0}}\right)^{1 / 2} A_{q}(x)\left(T_{\mathrm{amb}}-T\right)
\end{aligned}
$$

The solution to equations (6) and (7) requires knowledge of the heat transfer conductance $\lambda_{0}\left(P T / P_{0} T_{0}\right)^{1 / 2} A_{q}(x)$. Therefore, the next section will focus on how to estimate it.

\section{EVALUATION OF HEAT TRANSFER BETWEEN THE AIR AND THE CYLINDER WALLS}

Neglecting temperature and pressure variations with respect to their average values, an average heat transfer coefficient $\bar{\lambda}$ may be considered. With this approach, the average heat flow transferred through walls is

$$
\overline{\dot{Q}}=\bar{\lambda} A_{q}(x)\left(T_{\mathrm{amb}}-T\right)
$$

Substituting this equation in equations (1) and (2), the pressure and temperature evolution are given by

$$
\begin{aligned}
\frac{\mathrm{d} P}{\mathrm{~d} t}= & -\gamma \frac{P}{V} \frac{\mathrm{d} V}{\mathrm{~d} t}+\gamma \frac{R}{V} \dot{m}_{\mathrm{in}} T_{\mathrm{in}}-\gamma \frac{R}{V} \dot{m}_{\mathrm{out}} T \\
& -\frac{\gamma-1}{V} \bar{\lambda} A_{q}(x)\left(T-T_{\mathrm{amb}}\right) \\
\frac{\mathrm{d} T}{\mathrm{~d} t}= & \frac{T}{V} \frac{\mathrm{d} V}{\mathrm{~d} t}(1-\gamma)-\dot{m}_{\text {out }} \frac{R T^{2}}{V P}(\gamma-1) \\
& +\dot{m}_{\mathrm{in}} \frac{R T}{V P}\left(\gamma T_{\mathrm{in}}-T\right) \\
& -\frac{(\gamma-1) T}{P V} \bar{\lambda} A_{q}(x)\left(T-T_{\text {amb }}\right)
\end{aligned}
$$

If there is no mass flow entering or leaving the cylinder and when its piston is blocked at a position $x_{\mathrm{x}}$, the temperature equation reduces to

$$
\frac{\mathrm{d} T}{\mathrm{~d} t}=-\frac{(\gamma-1) T}{P V} \bar{k}\left(T-T_{\mathrm{amb}}\right)
$$

where $\bar{k}$ is an average thermal conductance defined as

$$
\bar{k}=\bar{\lambda} A_{q}\left(x_{\mathrm{x}}\right)
$$

Assuming once again that air is a perfect gas, equation (11) can be reduced to

$$
\frac{\mathrm{d} T}{\mathrm{~d} t}=-\frac{1}{\tau}\left(T-T_{\mathrm{amb}}\right)
$$

where

$$
\tau=\frac{c_{v} m}{\bar{k}}
$$

is the average thermal time constant of the system and $m$ is the mass of air inside the cylinder chamber. If the thermal time constant is experimentally estimated, then the thermal conductance can be determined solving for $\bar{k}$, which is given by

$$
\bar{k}=\frac{m c_{v}}{\tau}
$$

It is not straightforward, however, to obtain an experimental assessment of equation (13) since the bandwidth of commercially available temperature sensors is too narrow to obtain accurate measures. This problem is further magnified by the stillness of air during measurement. In order to circumvent it, 
note that similar reasoning to that above can be applied to the pressure equation (9), leading to

$$
\frac{\mathrm{d} P}{\mathrm{~d} t}=-\frac{1}{\tau}\left(P-\frac{m R}{V} T_{\mathrm{amb}}\right)
$$

where $\tau$ is also the thermal time constant defined in equation (14). Since the time evolution of equation (16) can be accurately measured using commercially available pressure sensors, an estimate of the thermal time constant can thus be obtained.

This approach was used in references [17], [24], and [25], where the thermal time constant was measured for several hydraulic accumulators with different preloading pressures in the following way: the gas charge pressure was suddenly changed by loading the accumulator with oil at a certain pressure. Measuring the pressure evolution of the gas as it relaxes by natural cooling to a stationary value gives an experimental evolution of equation (16), from which the thermal time constant can be estimated fitting a first-order model to the experimental data. The equation used on the regression is

$$
\hat{P}(t)=\hat{P}_{\mathrm{f}}+\Delta \hat{P} \mathrm{e}^{-t / \tau}
$$

In this equation, $\hat{P}_{\mathrm{f}}$ is the estimated final equilibrium pressure, $\Delta \hat{P}$ is the estimated difference between the initial and final pressures, and $\tau$ is the (average) thermal time constant.

Although the actual time constant is dependent on pressure and temperature, this procedure has been used in hydraulic accumulators [24] with good experimental results. Furthermore, it is argued in that study that this approach is better than using polytropic indexes since these vary not only with accumulator size and precharge pressure but also with the rates of compression and expansion.

The average temperature $T_{\mathrm{av}}$ and average pressure $P_{\mathrm{av}}$ of the experiment can be estimated from

$$
\begin{aligned}
& \hat{P}_{\mathrm{av}}=\frac{1}{t_{\mathrm{ss}}} \int_{0}^{t_{\mathrm{ss}}}\left(\hat{P}_{\mathrm{f}}+\Delta \hat{P} \mathrm{e}^{-t / \tau}\right) \mathrm{d} t \\
& \hat{T}_{\mathrm{av}}=\frac{1}{t_{\mathrm{ss}}} \int_{0}^{t_{\mathrm{ss}}}\left(\hat{T}_{\mathrm{f}}+\Delta \hat{T} \mathrm{e}^{-t / \tau}\right) \mathrm{d} t
\end{aligned}
$$

In this equation, $t_{\mathrm{ss}}$ is the time needed to reach the temperature and pressure steady state.

Since $\bar{k}$ was determined as the average thermal conductance in an experiment with average pressure and temperature $P_{\mathrm{av}}$ and $T_{\mathrm{av}}$, it is possible to estimate $k_{\text {av }}$ as

$$
\hat{k}_{\mathrm{av}}=\bar{k}
$$

Furthermore, the heat transfer coefficient at average conditions can be determined as

$$
\hat{\lambda}_{\mathrm{av}}=\frac{\hat{k}_{\mathrm{av}}}{A_{q}}
$$

Finally, the heat transfer coefficient referred to the equilibrium operating conditions is estimated from

$$
\hat{\lambda}_{0}=\hat{\lambda}_{\mathrm{av}}\left(\frac{P_{0} T_{0}}{\hat{P}_{\mathrm{av}} \hat{T}_{\mathrm{av}}}\right)^{1 / 2}
$$

Note that this procedure is based on the global heat transfer between the air inside the cylinder and the surrounding environment. However, as presented earlier, this global heat transfer is essentially constrained by the convection between the air and the inside cylinder wall. It is therefore reasonable to expect that this procedure provides a good estimate of both $k$ and $\lambda$. In order to check the consistency of this approach with pneumatic cylinders, the next section presents a simulation study where, starting from a value of $\lambda_{0}$ for the 'real' cylinder, $\hat{k}_{\mathrm{av}}, \hat{k}_{0}, \hat{\lambda}_{\mathrm{av}}$, and $\hat{\lambda}_{0}$ are determined using the thermal time constant method.

\subsection{Simulated evaluation of the heat transfer coefficient}

In this simulation a pneumatic cylinder $\left(P_{\mathrm{amb}}=\right.$ $1 \times 10^{5} \mathrm{~Pa}, T_{\mathrm{amb}}=293 \mathrm{~K}, \phi=20 \mathrm{~mm}, l=100 \mathrm{~mm}$, and $V_{\mathrm{d}}=1.57 \times 10^{-6} \mathrm{~m}^{3}$ ) started from its full length and was pushed by an external force up to an end stop at its half-length position, where it remained until its internal state reached stationary values (Fig. 2).

During the entire experiment, the inlet of the pressurized chamber was closed. It was assumed that the evolution of pressure is given by equation (6) with $\lambda_{0}=26.5 \mathrm{WK}^{-1} \mathrm{~m}^{-2}$ at $P_{0}=5.65 \times 10^{5} \mathrm{~Pa}$ and $T_{0}=293 \mathrm{~K}$ (see Appendix 2). The pressure response is plotted in Fig. 3.

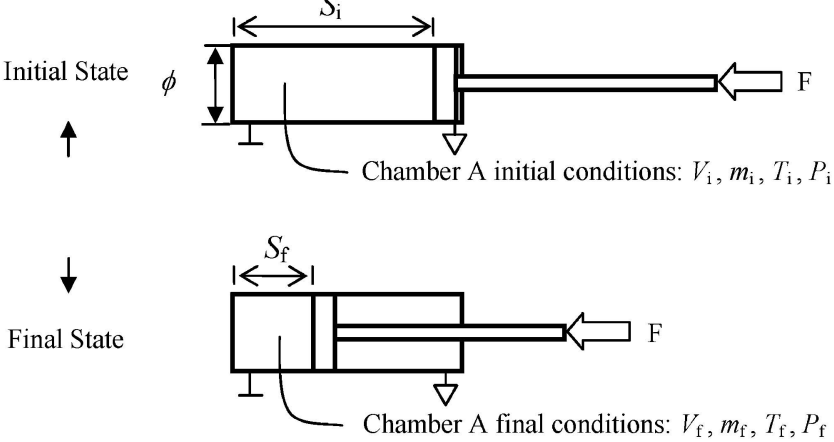

Fig. 2 Simulated evaluation of the heat transfer coefficient: initial and final states 


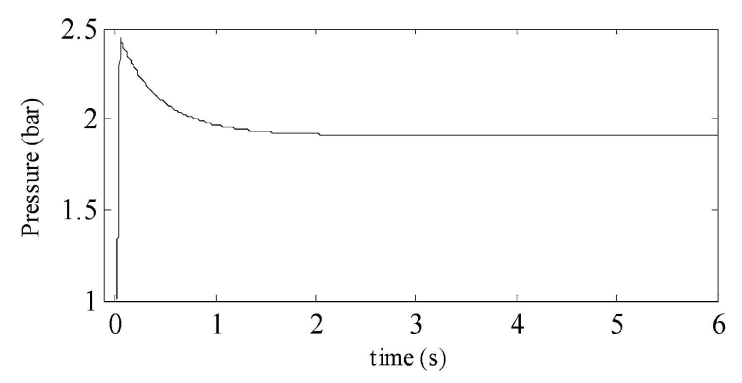

Fig. 3 Cylinder response to a simulated heat transfer determination experiment

The following steps provide a generic procedure that enables the estimation of the heat transfer coefficients $\lambda_{\mathrm{av}}, \lambda_{0}, k_{\mathrm{av}}$, and $k_{0}$.

Step 1. Fit a first-order equation to pressure data using least-squares minimization. Fitting firstorder equation (17) to the pressure data shown in Fig. 3 (blocked piston, after the peak value is achieved) gives

$$
\hat{P}(t)=1 \times 10^{5}\left(1.91+0.524 \mathrm{e}^{-t / 0.4292}\right)
$$

Step 2. Determine the mass of air inside the actuator chamber and its dead volume. Let $V_{\mathrm{i}}, m_{\mathrm{i}}, T_{\mathrm{i}}$, and $P_{\mathrm{i}}$ designate the initial (before the actuator was pushed) volume, mass of air, temperature, and pressure respectively in chamber A. Let $V_{\mathrm{f}}, m_{\mathrm{f}}$, $T_{\mathrm{f}}$, and $P_{\mathrm{f}}$ designate the same variables at final (rest) conditions. The volumes $V_{\mathrm{i}}$ and $V_{\mathrm{f}}$ can be estimated as

$$
\begin{aligned}
& \hat{V}_{\mathrm{i}}=V_{\text {cil_i }}+\hat{V}_{\mathrm{d}} \\
& \hat{V}_{\mathrm{f}}=V_{\text {cil_f }}+\hat{V}_{\mathrm{d}}
\end{aligned}
$$

The cylindrical volumes $V_{\text {cil_i }}=\pi \phi^{2} S_{\mathrm{i}} / 4$ and $V_{\text {cil_f }}=$ $\pi \phi^{2} S_{\mathrm{f}} / 4$ are defined for the initial extension $S_{\mathrm{i}}$ and final extension $S_{\mathrm{f}}$ of the actuator and $V_{\mathrm{d}}$ is the dead volume. Since the experiment is performed with chamber A inlet closed, $m_{\mathrm{i}}=m_{\mathrm{f}}=m$. On the other hand, since the experiment started and ended with a steady situation in chamber A, $T_{\mathrm{i}}=T_{\mathrm{f}}=T_{\mathrm{amb}}$. Applying the perfect gas state equation and eliminating the dead volume from equations (24) and (25), the mass inside the cylinder chamber can be estimated from

$$
\hat{m}=\frac{V_{\text {cyl_i }}-V_{\text {cyl_ff }}}{R T_{\text {amb }}} \frac{P_{\mathrm{i}} P_{\mathrm{f}}}{P_{\mathrm{f}}-P_{\mathrm{i}}}
$$

By applying once again the perfect gas law and substituting $m$ in equations (24) and (25), the dead volume can be estimated. For this particular case, $\hat{m}=39.2 \times 10^{-6} \mathrm{~kg}$ and $\hat{V}_{\mathrm{d}}=1.55 \times 10^{-6} \mathrm{~m}^{3}$.

Step 3. Determine the average thermal conductance. The average thermal conductance $k_{\mathrm{av}}$ can be estimated using equations (15) and (20). In the present case

$$
\hat{k}_{\mathrm{av}}=\frac{\hat{m} c_{v}}{\tau}=0.0656 \mathrm{~W} / \mathrm{K}
$$

Step 4. Determine the heat transfer area. The heat transfer area was estimated by considering twice the circular area of the piston plus the lateral area of a cylinder with length $4 V_{\mathrm{f}} /\left(\pi \phi^{2}\right)$ according to

$$
\hat{A}_{q}=\frac{4 \hat{V}_{\mathrm{f}}}{\phi}+\frac{\pi \phi^{2}}{2}
$$

In the present simulation, $\hat{A}_{q}=4.08 \times 10^{-3} \mathrm{~m}^{2}$.

Step 5. Determine the average heat transfer coefficient. Using equation (21), $\lambda_{\mathrm{av}}$ can be estimated as $\hat{\lambda}_{\mathrm{av}}=$ $\hat{k}_{\mathrm{av}} / \hat{A}_{q}$. In the present case, $\hat{\lambda}_{\mathrm{av}}=16.07 \mathrm{WK}^{-1} \mathrm{~m}^{-2}$.

Step 6. Determine the average pressure and temperature. Applying a 1 per cent criterion for the settling time of equation (23) gives $t_{\mathrm{ss}}=1.98 \mathrm{~s}$. Applying equation (18), the average pressure is $\hat{P}_{\text {av }}=2.023 \times 10^{5} \mathrm{~Pa}$. For the temperature evolution inside the chamber, applying the perfect gas law results

$$
\hat{T}(t)=\frac{\hat{V}_{\mathrm{f}}}{\hat{m} R} \hat{P}(t)
$$

where $\hat{P}(t)$ is given by equation (23). Applying equation (19) gives the average temperature $\hat{T}_{\mathrm{av}}=310.42 \mathrm{~K}$. Note that in this example the estimated final temperature is $293.6 \mathrm{~K}$; therefore the initial and final temperatures are almost equal and the assumption made in step 2 is valid.

Step 7. Determine the heat transfer coefficient and the thermal conductance at $P_{0}$ and $T_{0}$. Using equation (22), the estimated value of $\lambda_{0}$ at $P_{0}$ and $T_{0}$ is $\hat{\lambda}_{0}=26.16 \mathrm{WK}^{-1} \mathrm{~m}^{-2}$. Finally, the thermal conductance can be obtained using equation (21) at $P_{0}$ and $T_{0}: \hat{k}_{0}=0.107 \mathrm{~W} / \mathrm{K}$.

This simulation shows that the thermal time constant method is a simple and yet accurate way of estimating the heat transfer coefficient(s). In the example above, the relative difference between peak and steady values of pressure and temperature during the experiment is approximately 30 per cent; nevertheless, the error in the estimation of $\lambda_{0}$ using average values for those variables is only 1.3 per cent. However, as far as the present authors' knowledge goes, there is no study that experimentally evaluates the heat transfer coefficient for different pressures, temperatures, areas, and pneumatic cylinder types. 
Table 1 Main features of the pneumatic actuators used to determine experimentally the heat transfer coefficients

\begin{tabular}{lllllll}
\hline Actuator & Manufacturer & Reference & $\phi(\mathrm{mm})$ & $\phi_{\mathrm{h}}(\mathrm{mm})$ & $l(\mathrm{~mm})$ & Material \\
\hline A & Festo & DSNU20-100PPV-A & 20 & 8 & 100 & Stainless steel \\
B & Bosch & 0822400203 & 32 & 12 & 150 & Steel \\
C & Joucomatic & PES $32 \Omega 400$ R-DM & 32 & 12 & 400 & Aluminium alloy \\
\hline
\end{tabular}

\subsection{Experimental evaluation of the heat transfer coefficients}

Three different pneumatic industrial actuators (whose features are presented in Table 1) with different initial pressures of inside air were tested. The pressure signals were measured using a Druck PTX 1400 pressure transmitter and signal acquisition was performed at $100 \mathrm{~Hz}$ by a Computer Boards data acquisition card connected to a personal computer.

At the beginning of the experiments, each cylinder to be tested (cylinder 1) was extended or partially extended (initial situation in Fig. 4), with the primary chamber (chamber A) inlet closed and under a certain initial pressure $P_{\mathrm{i}}$. Then, cylinder 2 was fully extended, causing cylinder 1 to retract and attain the final situation shown in Fig. 4.

In each actuator two experiments using different initial pressures $P_{\mathrm{i}}$ were performed. To ensure statistical confidence, each experiment was repeated 10 times. Table 2 presents the average initial pressures for each cylinder and experiment and for the dimensions presented in Fig. 4. Figures 5 and 6 present the average of the ten sets of data collected with the piston blocked, after the pressure peak is attained, for each experiment and cylinder.
Table 2 Features of each experiment and actuator with respect to Fig. 4

\begin{tabular}{llllllll}
\hline & \multicolumn{3}{c}{$\begin{array}{c}\text { Experiment } 1 \text { for the } \\
\text { following actuators }\end{array}$} & & \multicolumn{3}{c}{$\begin{array}{c}\text { Experiment 2 for the } \\
\text { following actuators }\end{array}$} \\
\cline { 2 - 3 } & $\mathrm{A}$ & $\mathrm{B}$ & $\mathrm{C}$ & & $\mathrm{A}$ & $\mathrm{B}$ & $\mathrm{C}$ \\
\hline$P_{\mathrm{i}}(\mathrm{bar})$ & 1.01 & 1.01 & 1.01 & & 3.28 & 3.16 & 3.09 \\
$S_{\mathrm{i}}(\mathrm{mm})$ & 100 & 150 & 269 & & 100 & 150 & 269 \\
$S_{\mathrm{f}}(\mathrm{mm})$ & 50 & 83 & 169 & & 50 & 83 & 169 \\
$\phi_{1}(\mathrm{~mm})$ & 20 & 32 & 32 & & 20 & 32 & 32 \\
$\phi_{2}(\mathrm{~mm})$ & 20 & 32 & 32 & & 20 & 32 & 32 \\
\hline
\end{tabular}

Applying steps 1 to 7 presented in section 3.1 allows the estimation of the thermal time constant and heat transfer coefficient at $P_{0}$ and $T_{0}$. Table 3 presents the results for step 1 and Table 4 the results for steps 2 to 7 . Note that the dead volume presented in Table 4 includes not only air inside the cylinder but also air contained in the fittings and tubes that connect the cylinder to the valves. This external dead volume of air is desirably small in servopneumatic practice since otherwise the bandwidth of the system might be reduced. Therefore, the tubes and fittings of the experimental set-up have been kept as short as possible.

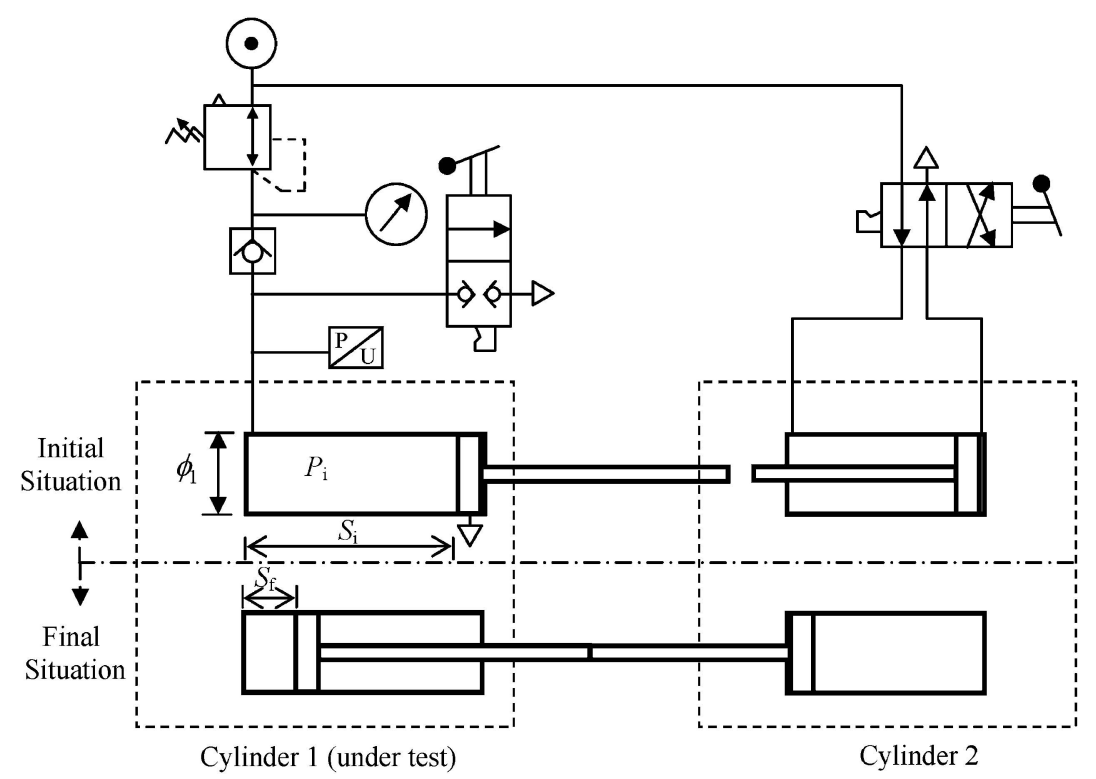

Fig. 4 Schematic diagram of the experimental set-up 

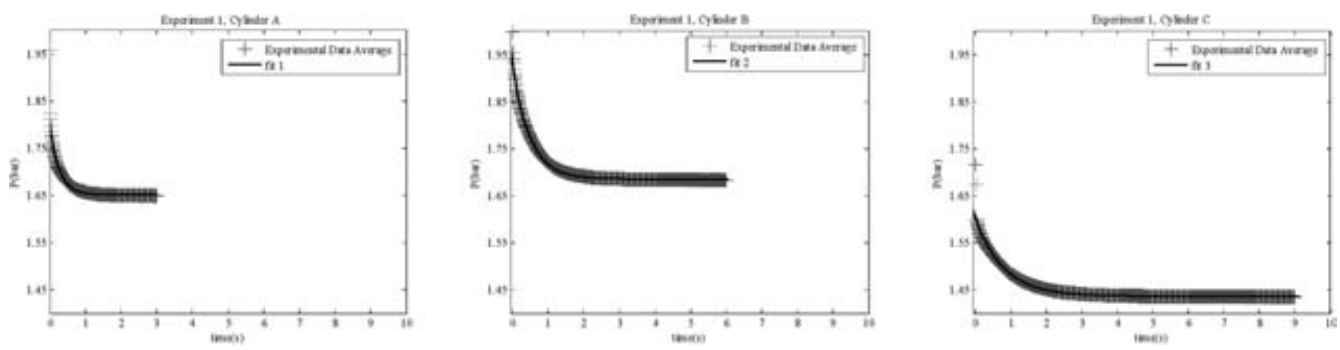

Fig. 5 Experimental data for experiment 1, cylinders A, B, and C
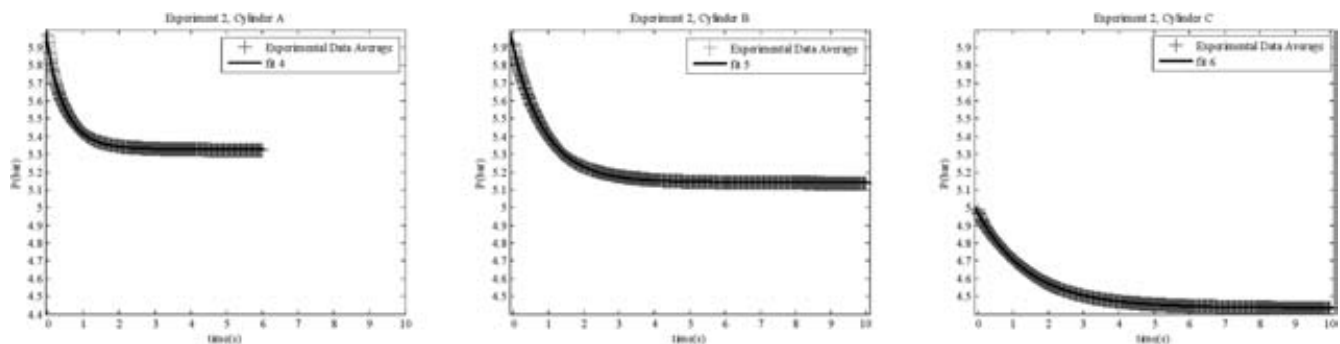

Fig. 6 Experimental data for experiment 2, cylinders A, B, and C

Table 3 Experimental data: regression results

\begin{tabular}{|c|c|c|c|c|c|c|}
\hline & \multicolumn{3}{|c|}{$\begin{array}{l}\text { Experiment } 1 \text { for the } \\
\text { following actuators }\end{array}$} & \multicolumn{3}{|c|}{$\begin{array}{l}\text { Experiment } 2 \text { for the } \\
\text { following actuators }\end{array}$} \\
\hline & A & B & $\mathrm{C}$ & A & B & $\mathrm{C}$ \\
\hline$\Delta \hat{P}$ (bar) & 0.178 & 0.246 & 0.164 & 0.583 & 0.757 & 0.534 \\
\hline$\hat{P}_{\mathrm{f}}($ bar $)$ & 1.652 & 1.686 & 1.436 & 5.329 & 5.142 & 4.436 \\
\hline$\tau(\mathrm{s})$ & 0.263 & 0.493 & 0.791 & 0.528 & 0.924 & 1.472 \\
\hline
\end{tabular}

The results presented in Table 4 may look, at a first glance, surprising. Indeed, the heat transfer coefficient decreases from cylinder A (stainless steel) to $\mathrm{B}$ (steel) to $\mathrm{C}$ (aluminium). This ordering is opposite to the thermal conductivity of current aluminium alloys, steel, and stainless steels [26]. There is, however a justification for this fact; as stated earlier, the temperature of the inside wall is essentially equal to ambient temperature and therefore the largest thermal resistance is that due to convection between the air and the cylinder. It can therefore be concluded that the cylinder material has a small influence on the heat transfer mechanism.
On the other hand, the geometrical properties of the air inside the pneumatic chamber seem to play an important role. Table 5 presents the final volume $\hat{V}_{\mathrm{f}}$, heat transfer area $\hat{A}_{q}$, the ratio $\hat{V}_{\mathrm{f}} / \hat{A}_{q}$, and the heat transfer coefficients $\hat{\lambda}_{0}$ listed in ascending order by the ratio $\hat{V}_{\mathrm{f}} / \hat{A}_{q}$. A general trend of decrease in the heat transfer coefficient with increase in this ratio can be seen. This makes sense since, for the same heat transfer area, the larger the volume of air, the more difficult heat transfer becomes. As a final remark, Eichelberg's model appears to capture correctly the heat transfer dependence on pressure and temperature since the estimates of the heat transfer coefficients $\lambda_{0}$ provided by both experiments are approximately the same for the same actuator.

\section{CONCLUSIONS}

This work has presented a simple and precise method to estimate the heat transfer between air inside a pneumatic cylinder chamber and its environment.

Table 4 Experimental data: masses of air, heat transfer areas, dead volumes, average temperatures and pressures, heat transfer coefficients, and thermal conductances

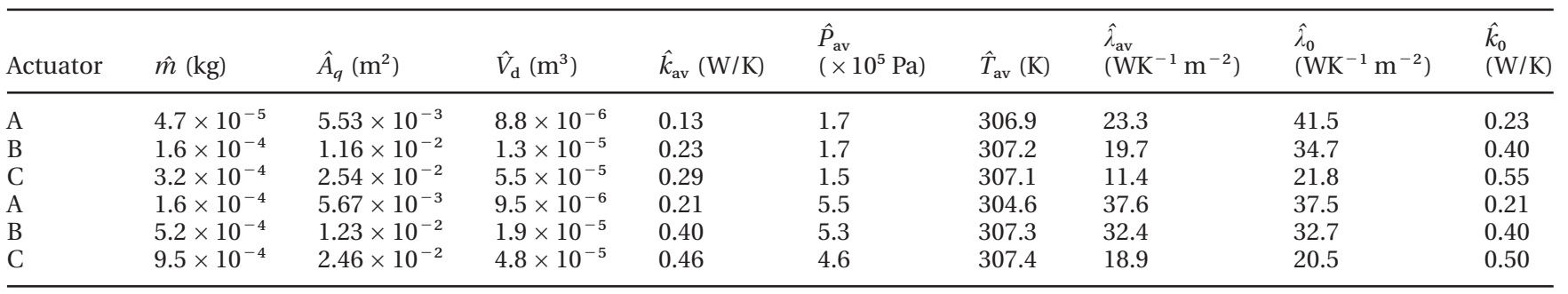


Table 5 Final volumes, heat transfer areas, ratios between them, and heat transfer coefficients

\begin{tabular}{|c|c|c|c|c|c|}
\hline Experiment & Cylinder & $\hat{V}_{\mathrm{f}}\left(\mathrm{m}^{3}\right)$ & $\hat{A}_{q}\left(\mathrm{~m}^{2}\right)$ & $\hat{V}_{\mathrm{f}} / \hat{A}_{q}\left(\times 10^{-3} \mathrm{~m}\right)$ & $\hat{\lambda}_{0}\left(\mathrm{WK}^{-1} \mathrm{~m}^{-2}\right)$ \\
\hline 1 & $\mathrm{~A}$ & $2.45 \times 10^{-5}$ & $5.53 \times 10^{-3}$ & 4.43 & 41.5 \\
\hline 2 & A & $2.52 \times 10^{-5}$ & $5.67 \times 10^{-3}$ & 4.45 & 37.5 \\
\hline 1 & $\mathrm{~B}$ & $7.97 \times 10^{-5}$ & $1.16 \times 10^{-2}$ & 6.89 & 34.7 \\
\hline 2 & B & $8.59 \times 10^{-5}$ & $1.23 \times 10^{-2}$ & 6.96 & 32.7 \\
\hline 2 & $\mathrm{C}$ & $1.84 \times 10^{-4}$ & $2.46 \times 10^{-2}$ & 7.48 & 20.5 \\
\hline 1 & $\mathrm{C}$ & $1.91 \times 10^{-4}$ & $2.54 \times 10^{-2}$ & 7.49 & 21.8 \\
\hline
\end{tabular}

Starting from the thermodynamic model of a pneumatic actuator chamber, the need to quantify the heat transfer was highlighted and a procedure to estimate it using an average thermal time constant was presented. The validity of this approach was shown by simulation studies. Three different industrial pneumatic cylinders were experimentally tested using this procedure. Results from this work can be applied to enhance industrial pneumatic actuator models, for both simulation and control purposes.

\section{ACKNOWLEDGEMENT}

This work has been partially funded by Fundação para a Ciência e Tecnologia under the programme POCTI.

\section{REFERENCES}

1 Paul, A., Mishra, J., and Radke, A. Reduced order sliding mode control for pneumatic actuator. IEEE Trans. Control System Technol., 1994, 2(3), 271-276.

2 Pandian, S., Takemura, F., Hayakawa, Y., and Kawamura, S. Pressure observer-controller design for pneumatic actuators. IEEE/ASME Trans. Mechatronics, 2002, 7(4), 490-499.

3 Ning, S. and Bone, G. M. High steady-state accuracy pneumatic servo positioning system with PVA/PV control and friction compensation. In Proceedings of the IEEE International Conference on Robotics and automation, Washington, DC, USA, 2002, pp. 2824-2829 (IEEE, New York).

4 Outbib, R. and Richard, E. State feedback stabilization of an electropneumatic system. Trans. ASME, J. Dynamic Systems, Measmt, Control, 2000, 122(3), 410-415.

5 Norgaard, M., Ravn, O., Poulsen, N. K., and Hansen, L. K. Neural networks for modelling and control of dynamic systems, 2003 (Springer-Verlag, Berlin).

6 Ye, N., Betemps, M., Scavarda, S., and Jutard, A. A servocontrolled pneumatic actuator for small movement-application to an adaptive gripper. In Proceedings of the Fifth International Conference on Advanced robotics, 1991, pp. 1582-1585 (IEEE-ICAR, Pisa, Italy).
7 Varseveld, R. and Bone, G. M. Accurate position control of a pneumatic actuator using on/off solenoid valves. IEEE/ASME Trans. Mechatronics, 1997, 2(3), 195-204.

8 McCloy, D. and Martin, H. R. Control of fluid power: analysis and design. Engineering science, 1980 (Ellis Horwood, Chichester, West Sussex).

9 Karnopp, D. Computer simulation of stick-slip friction in mechanical dynamic systems. Trans. ASME, J. Dynamic Systems, Measmt, Control, 1985, 107, 100-107.

10 Richer, E. and Hurmuzlu, Y. A high performance pneumatic force actuator system: Part I - nonlinear mathematical model. Trans. ASME, J. Dynamic Systems, Measmt, Control, 2000, 122(3), 416-425.

11 Brun, X. Commandes linéaires et non linéaires en électropneumatique. Methodologies et applications, $\mathrm{PhD}$ Thesis, Institut National des Sciences Appliquées, Lyon, France, 1999.

12 Det, F. Modelisation en bond graphs simulation et commande d'une pince a souder electropneumatique. $\mathrm{PhD}$ Thesis, Institut National des Sciences Appliquées, Lyon, France, 1991.

13 Burrows, C. R. Effect of position on the stability of pneumatic servosystems. Proc. Instn Mech. Engrs, Part C: J. Mechanical Engineering Science, 1969, $11(6), 615-616$.

14 Zalmazon, L. A. Components for pneumatic control instruments, 1965 (Pergamon, Oxford).

15 Andersen, B. W. The analysis and design of pneumatic systems, 1976 (John Wiley, New York).

16 Chitty, A. and Lambert, T. H. Modelling a loaded two way pneumatic actuator. J. Measmt Control, 1976, 9(1), 19-25.

17 Otis, D. R. and Pourmovahead, A. An experimental thermal time constant correlation for hydraulic accumulators. Trans. ASME, J. Dynamic Systems, Measmt, Control, 1990, 112, 116-121.

18 Pourmovahed, A. and Otis, D. R. Effects of thermal damping on the dynamic response of a hydraulic motor-accumulator system. Trans. ASME, J. Dynamic Systems, Measmt, Control, 1984, 106, 21-26.

19 De Las Heras, S. Gas compression process inside oleopneumatic suspensions. In Proceedings of the 47th National Conference on Fluid Power, 1996, pp. 11-18 (National Fluid Power Association, Chicago, Illinois).

20 White, F. Fluid mechanics, 1994 (McGraw-Hill, New York). 
21 Richard, E. De la commande lineaire et non lineaire en position des systems electropneumatiques. $\mathrm{PhD}$ Thesis, Institut National des Sciences Appliquées, Lyon, France, 1990.

22 Catto, A. G. and Prata, A. T. A numerical study of instantaneous heat transfer during compression and expansion in piston-cylinder geometry. Numer. Heat Transfer, Part A, 2000, 38, 281-303.

23 Eichelberg, G. Some new investigations of old combustion engine problems. Engineering, 1939, 148(27), 463-466.

24 Otis, D. R. New developments in predicting and modifying performance of hydraulic accumulators. In Proceedings of the National Conference on Fluid power, 1974, pp. 473-489 (National Fluid Power Association).

25 Green, W. Accumulator time constants and the 'index' method: some comparisons based on experimental data. In Proceedings of the 35th National Conference on Fluid power, 1979, pp. 231-238 (National Fluid Power Association).

26 Incropera, F. and Witt, D. Fundamentals of heat and mass transfer, 2001 (John Wiley, New York).

\section{APPENDIX 1}

\section{Notation}

$A_{q} \quad$ heat transfer area $\left(\mathrm{m}^{2}\right)$

$A_{1}, A_{2} \quad$ servovalve restriction areas $\left(\mathrm{m}^{2}\right)$

$c_{v} \quad$ specific heat at constant volume $(\mathrm{J} / \mathrm{kg} \mathrm{K})$

$k \quad$ thermal conductance $(\mathrm{W} / \mathrm{K})$

$l \quad$ actuator stroke ( $\mathrm{mm})$

$m \quad$ mass of air inside the actuator chamber (kg)

$m_{\mathrm{i}}, m_{\mathrm{f}} \quad$ initial and final masses respectively of the air in chamber A $(\mathrm{kg})$

$P \quad$ absolute pressure inside the actuator chamber $(\mathrm{Pa})$

$P_{\text {amb }} \quad$ absolute ambient pressure $(\mathrm{Pa})$

$P_{\text {av }} \quad$ absolute average pressure $(\mathrm{Pa})$

$P_{\mathrm{A}}, P_{\mathrm{B}} \quad$ absolute pressures in chambers $\mathrm{A}$ and $B$ respectively $(\mathrm{Pa})$

$P_{\mathrm{i}}, P_{\mathrm{f}} \quad$ absolute initial and final equilibrium pressures respectively of chamber $\mathrm{A}(\mathrm{Pa})$

$P_{\mathrm{s}} \quad$ absolute supply pressure $(\mathrm{Pa})$

$P_{0} \quad$ absolute equilibrium pressure $(\mathrm{Pa})$

$R \quad$ perfect gas constant for air $(\mathrm{J} / \mathrm{kg} \mathrm{K})$

$S_{\mathrm{f}} \quad$ final rod extension (m)

$S_{\mathrm{i}} \quad$ initial rod extension $(\mathrm{m})$

$t_{\mathrm{ss}} \quad$ settling time (s)

$T$ temperature inside the actuator chamber $(\mathrm{K})$

$T_{\mathrm{amb}} \quad$ room temperature (K)

$T_{\mathrm{av}} \quad$ average temperature $(\mathrm{K})$

$T_{\mathrm{i}}, T_{\mathrm{f}} \quad$ initial and final equilibrium temperatures respectively $(\mathrm{K})$
$T_{\text {in }} \quad$ temperature of the air entering the actuator $(\mathrm{K})$

$T_{\mathrm{s}} \quad$ temperature of the source air (K)

$T_{0} \quad$ equilibrium temperature $(\mathrm{K})$

$V \quad$ volume of the actuator chamber $\left(\mathrm{m}^{3}\right)$

$V_{\text {cil_i }}, V_{\text {cil_f }}$ initial and final cylindrical volumes respectively of chamber $\mathrm{A}\left(\mathrm{m}^{3}\right)$

$V_{\mathrm{d}} \quad$ dead volume $\left(\mathrm{m}^{3}\right)$

$V_{\mathrm{i}}, V_{\mathrm{f}} \quad$ initial and final volumes respectively of the actuator chamber $\mathrm{A}\left(\mathrm{m}^{3}\right)$

$x_{\mathrm{x}} \quad$ fixed position of the piston (m)

$x, \dot{x} \quad$ piston displacement (m) and velocity $(\mathrm{m} / \mathrm{s})$

ratio of specific heats

heat transfer coefficient $\left(\mathrm{WK}^{-1} \mathrm{~m}^{-2}\right)$

average thermal time constant (s)

cylinder piston diameter $(\mathrm{mm})$

cylinder rod diameter $(\mathrm{mm})$

average value

estimated value

\section{APPENDIX 2}

\section{Equilibrium pressure and temperature}

At steady state conditions the temperature inside the cylinder is equal to the ambient temperature, assumed to be $293 \mathrm{~K}$. Therefore, the equilibrium temperature is $T_{0}=293 \mathrm{~K}$. In what concerns equilibrium pressure, consider the half-bridge model of a servovalve represented in Fig. 7 [21]. $\dot{m}_{1}$ and $\dot{m}_{2}$ represent the leakages of restriction 1 and restriction 2 respectively (see Fig. 7) and the spool is at central position. At equilibrium $T_{\mathrm{s}}=T=T_{0}, A_{1}=A_{2}$, and $\dot{m}_{1}=\dot{m}_{2}$. In the typical situation where $P_{\mathrm{s}} \geqslant 3.6 P_{\mathrm{atm}}$, there are three possible situations: $P=P_{1}, P_{1} \in\left[0.5283 P_{\mathrm{s}}, P_{\mathrm{s}}\right]$, $P=P_{2}, P_{2} \in\left[1 / 0.5283 P_{\text {atm }}, 0.5283 P_{\mathrm{s}}\left[\ldots\right.\right.$ and $P=P_{3}, P_{3} \in$ $\left[P_{\text {atm }}, 1 / 0.5283 P_{\text {atm }}\left[\ldots\right.\right.$ In the first situation, $\dot{m}_{1}$ is subsonic and $\dot{m}_{2}$ is sonic. In the second situation, $\dot{m}_{1}$ and $\dot{m}_{2}$ are sonic, and, in the third, $\dot{m}_{1}$ is sonic and $\dot{m}_{2}$ is subsonic (the reader is referred to reference [8] for details of sonic and subsonic flow).

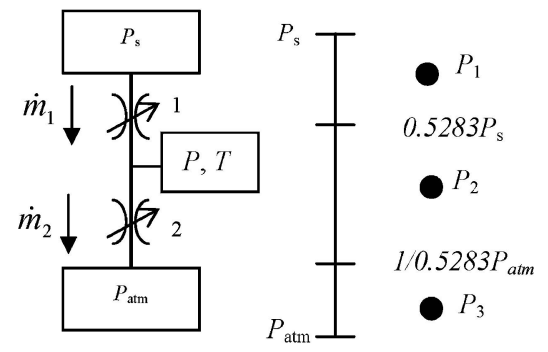

Fig. 7 Half-bridge model of a servovalve 
Equalizing $\dot{m}_{1}$ and $\dot{m}_{2}$ in the first situation gives

$$
\begin{gathered}
A_{1} P_{\mathrm{s}}\left\{\frac{2 \gamma}{(\gamma-1) R T_{\mathrm{s}}}\left[\left(\frac{P}{P_{\mathrm{s}}}\right)^{2 / \gamma}-\left(\frac{P}{P_{\mathrm{s}}}\right)^{(\gamma+1) / \gamma}\right]\right\}^{1 / 2} \\
=\frac{2}{\gamma+1}^{1 /(\gamma-1)}\left[\frac{2 \gamma}{(\gamma-1) R}\right]^{1 / 2} \frac{P A_{2}}{T^{1 / 2}}
\end{gathered}
$$

The solution for equation (29) when the fluid is air gives $P=0.8077 P_{\mathrm{s}}$. Note that the same exercise applied to the second and third situations would result in false propositions. In this work a supply pressure $P_{\mathrm{s}}=7 \times 10^{5} \mathrm{~Pa}$ has been assumed, and therefore the equilibrium pressure is $P_{0}=5.65 \times 10^{5} \mathrm{~Pa}$. 
Copyright of Proceedings of the Institution of Mechanical Engineers -- Part I -- Journal of Systems \& Control Engineering is the property of Professional Engineering Publishing and its content may not be copied or emailed to multiple sites or posted to a listserv without the copyright holder's express written permission. However, users may print, download, or email articles for individual use. 